\title{
AS VOZES E OS SUSSURROS DAS PAREDES DE PORTO ALEGRE
}

\author{
Ricardo Campos ${ }^{1}$
}

Este é um ensaio visual que decorre de um curto período de estadia na cidade de Porto Alegre (Rio Grande do Sul), no âmbito do convite que me foi endereçado pela professora Cornélia Eckert, para desenvolver um conjunto de actividades junto do Navisual, em Maio de 2017. Este foi um período bastante frutífero, quer no que respeita a um primeiro contacto com o meio da Arte Urbana na cidade ${ }^{2}$, quer no que respeita ao estudo do tipo de expressões existente. No decurso desta primeira exploração, foram realizadas algumas caminhadas urbanas, desenhadas pelo pesquisador do Navisual Junior Abalos, em função das particularidades das inscrições e expressões artísticas existentes nos diversos territórios. Se, por um lado, observámos circuitos mais formais, organizados e legitimados de arte urbana, apoiados pelos poderes públicos, por outro lado, tivemos a oportunidade de nos confrontar com apropriações territoriais espontâneas, informais, ilegais e inusitadas, revelando até que ponto as inscrições urbanas podem ter um carácter indomável. No primeiro caso podemos claramente colocar como exemplo o "Zis-Grafite" nos bairros do $4^{\circ}$ distrito ${ }^{3}$ quando, no segundo caso, podemos incluir a "Cidade baixa", um território que pelas suas características e paisagem visual, me recordou a situação do Bairro Alto lisboeta há cerca de uma década $^{4}$ (Campos, 2009, 2010)

A questão do graffiti e da arte urbana é algo que me é bastante familiar, desde há mais de uma década. Acerca deste tema tenho uma visão simultaneamente próxima e de dentro, em função da exploração etnográfica que realizei na sequência do meu projecto de doutoramento (Campos, 2010), mas igualmente recuada que decorre do olhar marcado pelo tempo, pela observação distanciada das mudanças que se foram operando ao longo de mais de uma década. A partir da minha experiência gostaria de destacar

\footnotetext{
${ }^{1}$ Universidade Nova de Lisboa, Portugal.

2 Importante referir a este propósito a prestável e crucial colaboração de Tridente, Trampo e André Venzon. A eles um agradecimento especial pela disponibilidade e simpatia.

${ }^{3}$ Este é um roteiro turístico-cultural organizado em torno de diferentes obras de Arte Urbana, num território que se encontra em transformação, no sentido de criar as condições para o desenvolvimento de um bairro criativo na cidade de Porto Alegre.

${ }^{4}$ Este é um território marcado por uma intensa actividade ligada ao lazer nocturno, nomeadamente juvenil, sendo que nas paredes se encontram registos da passagem de muitos destes jovens, nas pixações, adesivos ou grafite. Esta situação assemelha-se áquilo que encontrei no Bairro Alto em Lisboa e que foi debatido no seguinte artigo: http://www.fcsh.unl.pt/revistas/arquivos-damemoria/ArtPDF/RicardoCamposAM5.pdf
} 
duas questões. Por um lado, o facto de estarmos perante um fenómeno global, inspirado num conjunto de expressões e práticas culturais surgidas na década de 60 nos EUA (Cooper e Chalfant, 1984; Castleman, 1982) que, entretanto, se foram dispersando pelo planeta, metamorfoseando-se em função desta viagem geográfica e temporal. Ou seja, estamos perante um conjunto de expressões de natureza global, com conexões evidentes à cultura graffiti norte-americana, mas que se foi transformando dando a origem a muitas outras técnicas e expressões. Por outro lado, este olhar mais macroscópico que tende a encontrar as regularidades e proximidades desta cultura global, não deve ignorar as singularidades locais que se encontram nos diversos territórios, marcados por contextos urbanos, sociais, culturais e políticos específicos e que se refletem na forma como o espaço urbano é apropriado. Ou seja, o graffiti, a arte urbana e as diferentes inscrições no espaço público, são um espelho das diferentes comunidades que habitam o espaço urbano. Deste modo, a pixação é um fenómeno tipicamente brasileiro, surgido num contexto social e urbano específico (Pereira, 2012, 2013). De igual modo, o inevitável "Fora Temer", só poderia ser justificado como sintoma do período de crise política brasileira ${ }^{5}$, tal como o "Área indígena"6 que encontramos em Porto Alegre, remete para a problemática dos povos indígenas no Brasil contemporâneo. Ou seja, quero com isto dizer que as paredes de uma cidade são uma expressão da história e da cultura de um povo e das comunidades que dele fazem parte, nelas estão inscritas vozes diversas que pretendem transmitir múltiplas mensagens e estados de alma. Da revolta e angústia manifestas na acusação de "Golpistas" e "Fora Temer", passando pelas dedicatórias de amor e pela inspiração evidente em fragmentos poéticos, desenhos ou pinturas, muitos são os exemplos de criatividade do cidadão comum.

Mas as paredes comunicam em diferentes tonalidades e volumes. Assim, há escritos e imagens que se impõem na forma de grito, tal é o seu volume e destaque na paisagem visual, forçando-nos a olhar. Estas são as expressões que lutam pela visibilidade, que procuram destacar-se pelo tamanho e posicionamento, no meio de um ecossistema visual saturado de imagens e estímulos visuais. Mas também encontramos no espaço público mensagens que nos convidam a uma comunicação mais próxima, dada a sua pequenez ou detalhe. São uma espécie de sussurro. Não se conseguem ver à

\footnotetext{
${ }^{5}$ Os períodos de crise e turbulência política são especialmente ricos em expressões políticas informais e transgressoras no espaço público urbano, como ficou evidente em contextos recentes (Campos, 2017; Zaimakis, 2015; Yanick, 2015).

${ }^{6}$ Referência ao trabalho do artista Xadalu, nomeadamente aos posters que se encontram espalhados pela cidade.
} 
distância, apenas se revelam aos olhares mais atentos e a uma exploração de proximidade. Assim, ao aproximarmo-nos das paredes vislumbramos um conjunto de mensagens diversas, em articulação ou sobreposição, fazendo emergir distintas estórias e memórias.

Este ensaio visual que aqui apresento é fruto de um primeiro olhar sobre a cidade de Porto Alegre. É revelador, por um lado, da visão curiosa do estrangeiro, daquele que explora com o olhar uma cidade desconhecida. Mas é, também, resultado do olhar do académico que procura regularidades, conexões conceptuais e empíricas com outros contextos de pesquisa. Um olhar que decorre quer das caminhadas espontâneas, livres e sem destino que realizei pela cidade, quer das incursões organizadas com circuito pré-programado, de acordo com critérios de natureza conceptual. Procurei, principalmente, uma perspectiva fotográfica de proximidade, de detalhe, atenta aos suportes, ao conteúdo das mensagens, à sobreposição de linguagens e técnicas, dando conta da polifonia de vozes e sussurros.
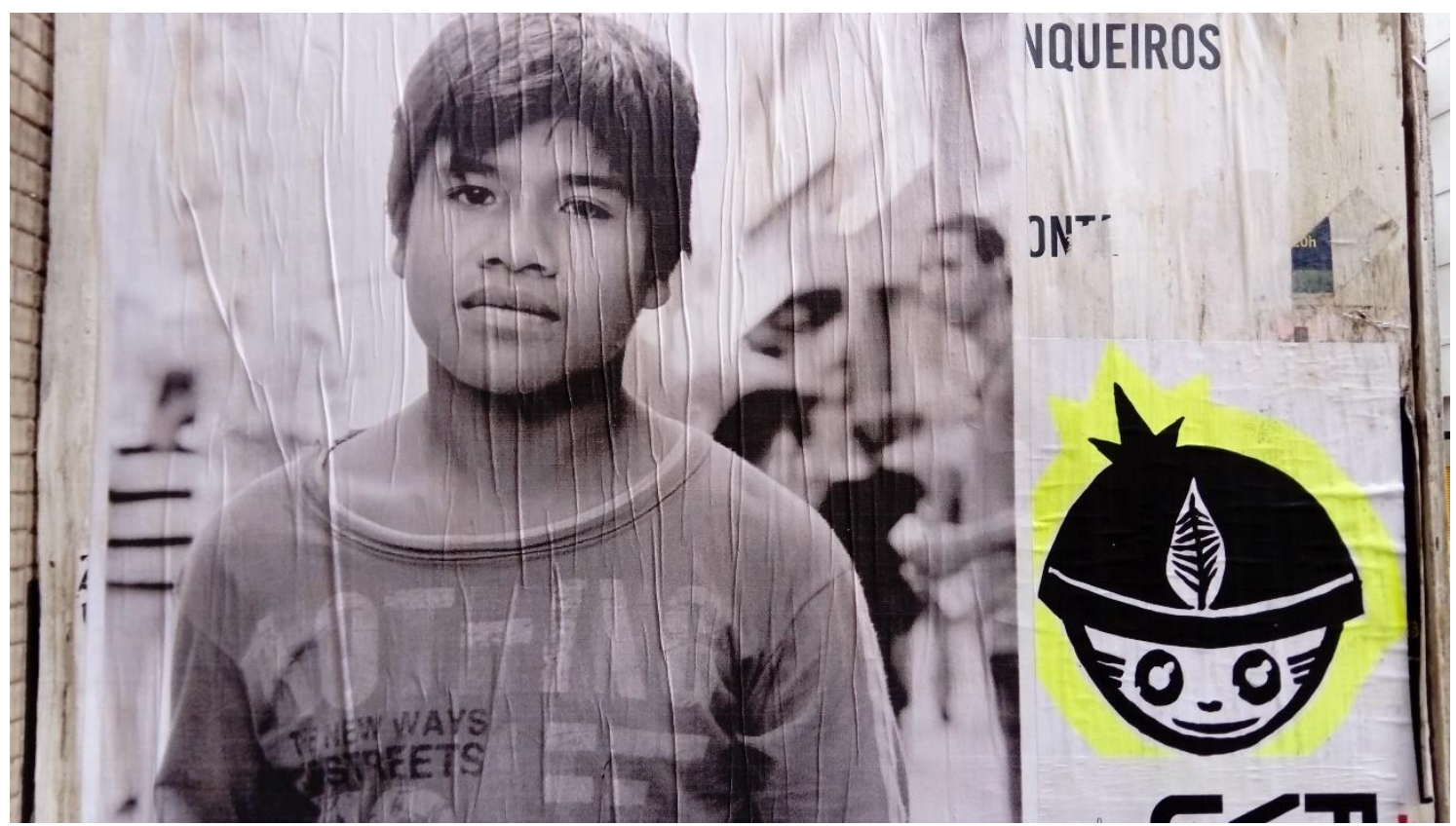

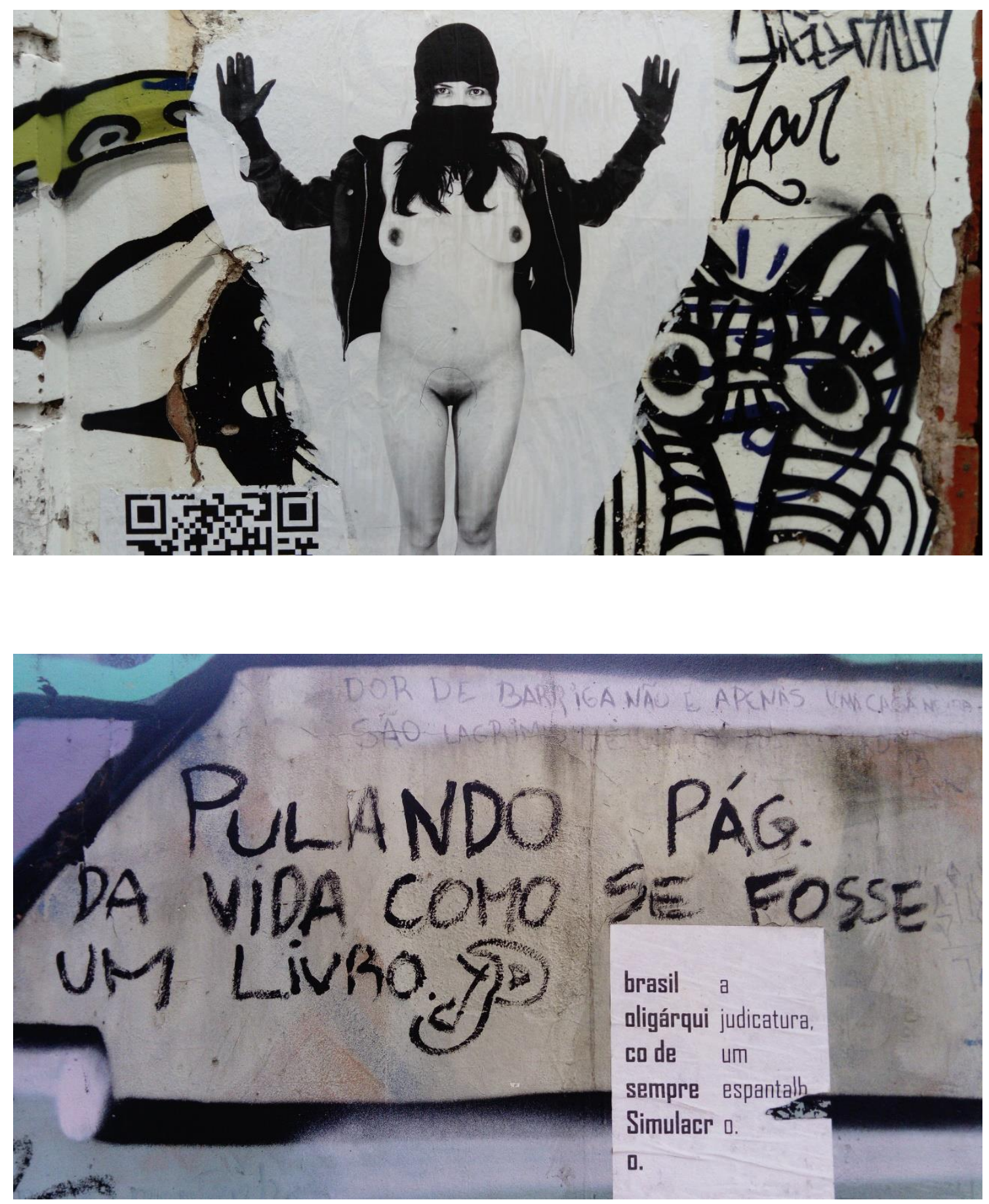

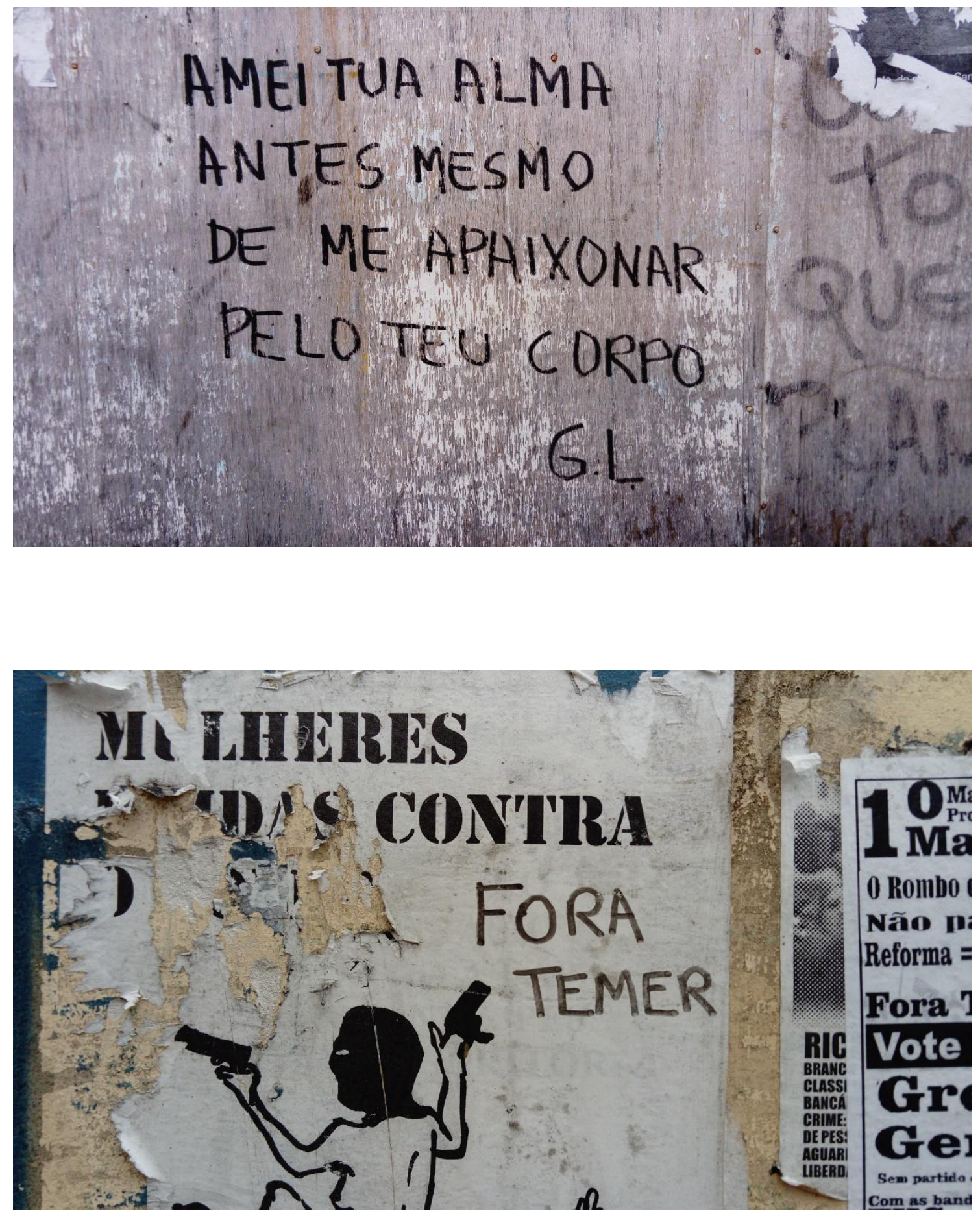

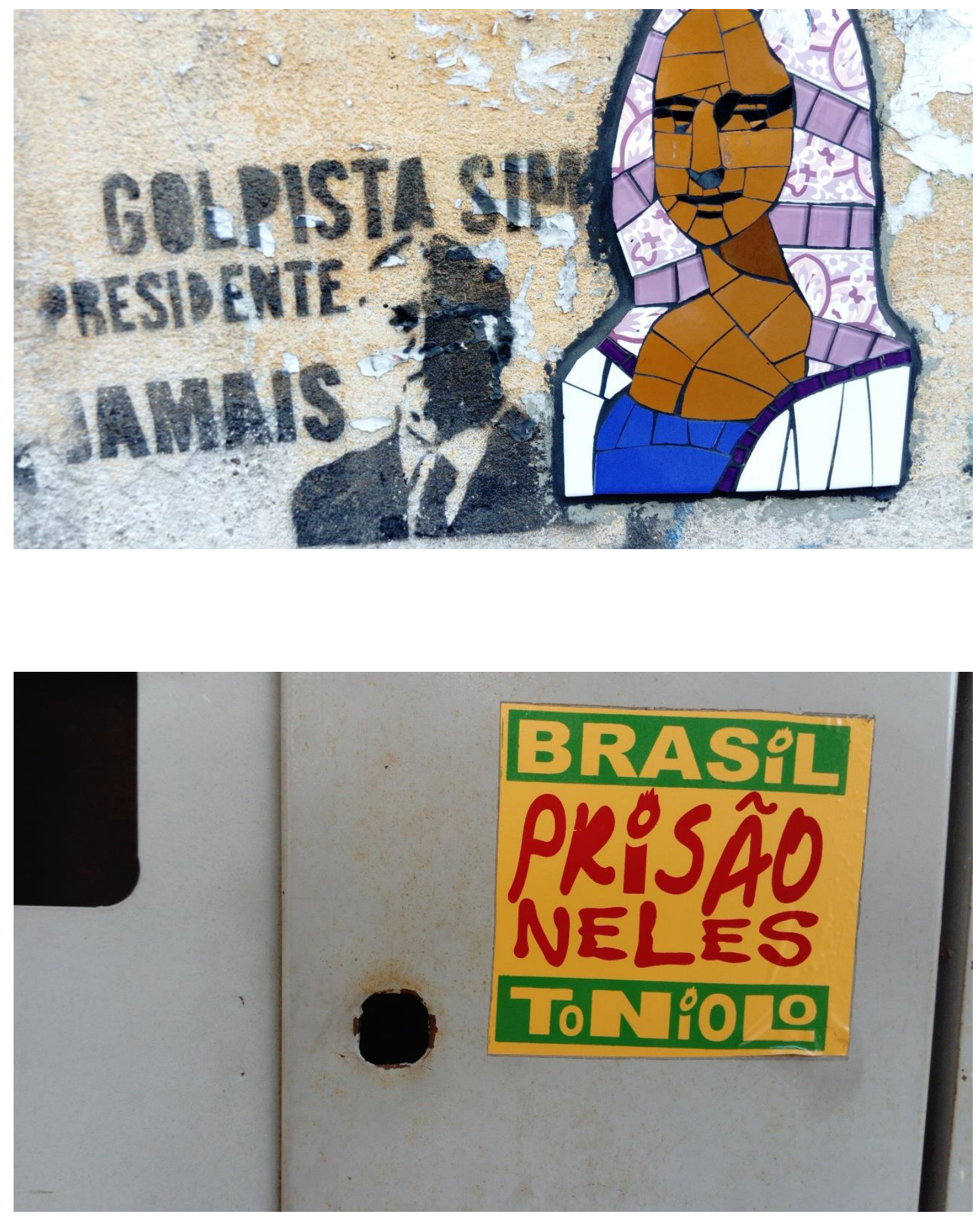


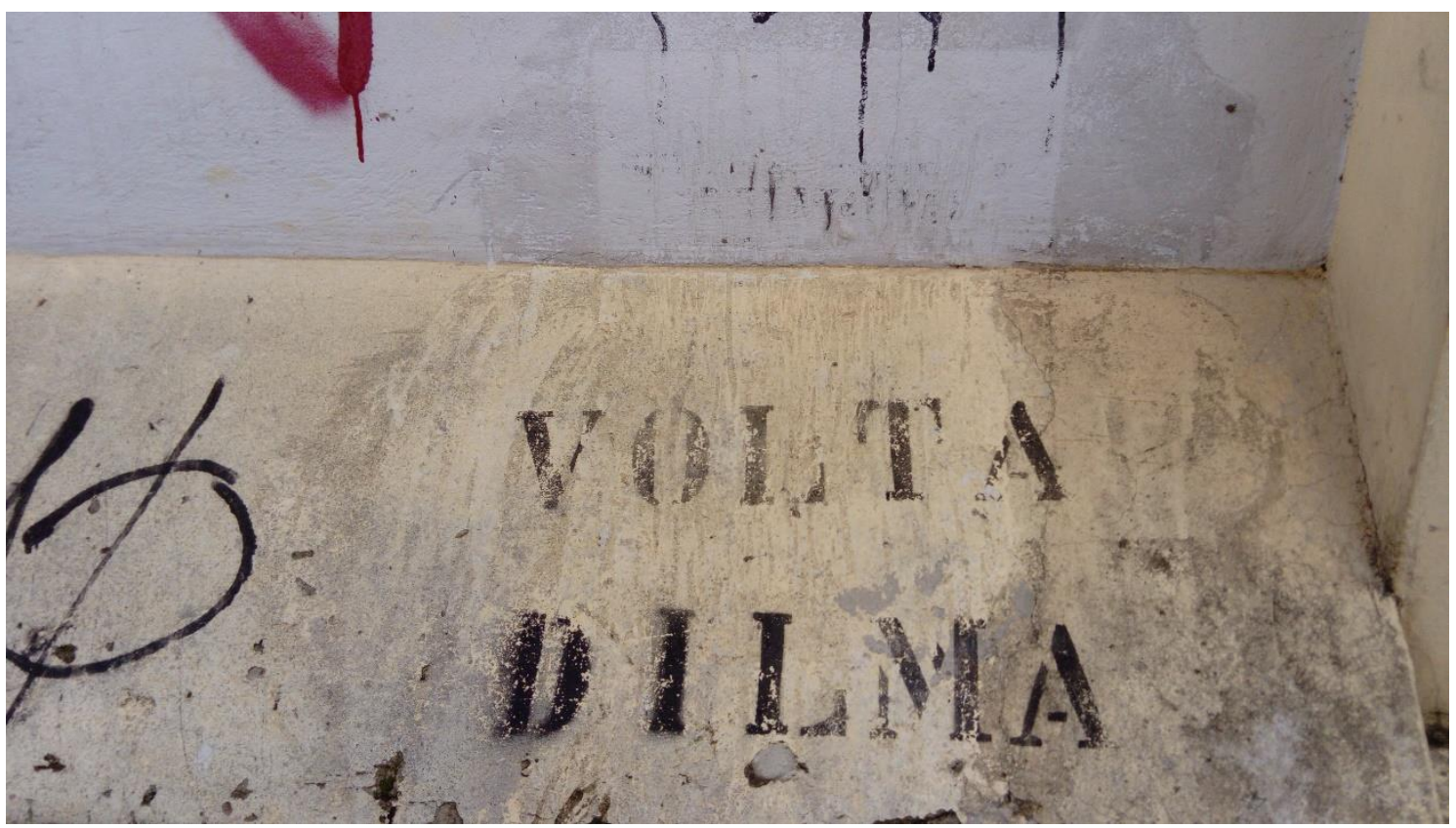

\section{Referências}

CAMPOS, Ricardo (2016) "From Marx to Merkel. Political muralism and graffiti in Lisbon." In. Jeffrey Ian Ross (Org.), Routledge Handbook of Graffiti and Street Art, 301-317. London \& New York: Routledge.

2010, Porque pintamos a cidade? Uma abordagem etnográfica ao graffiti urbano, Lisboa: Fim de Século.

2009, «A imagem é uma arma, a propósito de riscos e rabiscos no Bairro Alto», Arquivos da Memória, No 5/6 (Nova Série): 47-71.

CASTLEMAN, C. (1982) Getting Up - subway graffiti in New York. Massachusetts: MIT Press. COOPER, Martha e Chalfant, H. (1984), Subway Art. Londres: Thames \& Hudson.

PEREIRA, Alexandre B. (2013) Cidade de riscos: Notas etnográficas sobre pixação, adrenalina, morte e memória em São Paulo. Revista de Antropologia (USP. Impresso), v. 56, p. 81-110.

. (2012). Quem não é visto, não é lembrado: sociabilidade, escrita, visibilidade e memória na São Paulo da pixação. Cadernos de Arte e Antropologia, v. 1, p. 55-69.

YANIK, Lerna (2015) "Humor as Resistance? A Very Short Analysis of the Gezi Park Protest Graffiti." In Everywhere Taksim. Sowing the Seeds for a New Turkey at Gezi, edited by Isabel David and Kumru F. Toktamış, 153-184. Amsterdam: Amsterdam University Press.

ZAIMAKIS, Yiannis (2015) “'Welcome to the civilization of fear': on political graffiti heterotopias in Greece in times of crisis." Visual Communication 14 (4): 373-396.

Recebido em: 23/05/2017.

Aprovado em: 01/08/2017. 